\title{
Disentangling linear and nonlinear brain responses to evoked deep tissue pain
}

\section{Citation}

Loggia, Marco L., Robert R. Edwards, Jieun Kim, Mark G. Vangel, Ajay D. Wasan, Randy L. Gollub, Richard E. Harris, Kyungmo Park, and Vitaly Napadow. 2012. “Disentangling Linear and Nonlinear Brain Responses to Evoked Deep Tissue Pain." Pain 153 (10) (October): 2140-2151. doi:10.1016/j.pain.2012.07.014.

\section{Published Version}

doi:10.1016/j.pain.2012.07.014

\section{Permanent link}

http://nrs.harvard.edu/urn-3:HUL.InstRepos:36303922

\section{Terms of Use}

This article was downloaded from Harvard University's DASH repository, and is made available under the terms and conditions applicable to Other Posted Material, as set forth at http:// nrs.harvard.edu/urn-3:HUL.InstRepos:dash.current.terms-of-use\#LAA

\section{Share Your Story}

The Harvard community has made this article openly available.

Please share how this access benefits you. Submit a story.

\section{Accessibility}




\title{
Disentangling linear and nonlinear brain responses to evoked deep tissue pain
}

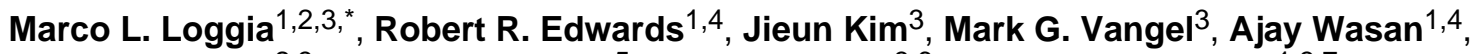 \\ Randy L. Gollub ${ }^{2,3}$, Richard E. Harris ${ }^{5}$, Kyungmo Park ${ }^{3,6}$, and Vitaly Napadow ${ }^{1,3,7}$ \\ ${ }^{1}$ Department of Anesthesiology, Perioperative and Pain Medicine, Brigham and Women's \\ Hospital, Harvard Medical School (HMS), Boston, MA \\ ${ }^{2}$ Department of Psychiatry, Massachusetts General Hospital, HMS, Boston, MA \\ ${ }^{3} \mathrm{MGH} / \mathrm{MIT} / \mathrm{HMS}$ Athinoula A. Martinos Center for Biomedical Imaging, Charlestown, MA \\ ${ }^{4}$ Department of Psychiatry, Brigham and Women's Hospital, HMS, Boston, MA \\ ${ }^{5}$ Chronic Pain and Fatigue Research Center, Department of Anesthesiology, University of \\ Michigan, Ann Arbor, Ml \\ ${ }^{6}$ Department of Biomedical Engineering, Kyunghee University, Yongin, Korea \\ ${ }^{7}$ Department of Radiology, Logan College of Chiropractic, Chesterfield, MO
}

\begin{abstract}
Pain stimuli evoke widespread responses in the brain. However, our understanding of the physiological significance underlying heterogeneous response within different pain-activated and deactivated regions is still limited. Using functional MRI, we evaluated brain responses to a wide range of stimulus intensity levels ( 1 innocuous, 7 painful) in order to estimate region-specific stimulus-response functions, which we hypothesized could illuminate that region's functional relationship to pain. Linear and nonlinear brain responses to pain were estimated through independent Legendre polynomial transformations of pain ratings within a general linear model. This approach identified at least five different, regionally-specific activity profiles in the brain. Linearly increasing (e.g., primary somatosensory/motor cortex, insulae) and intensity-independent (e.g., secondary somatosensory cortex) activation was noted in traditional pain processing areas, potentially reflecting sensory encoding and all-or-none salience responses, respectively. Multiple activity profiles were seen in areas of the default mode network (DMN): intensity-independent deactivation (e.g., posterior cingulate cortex), linearly decreasing (e.g., contralateral inferior parietal lobule), and quadratic (U-shaped; e.g., medial prefrontal cortex). The latter observation suggests that: 1) different DMN subregions exhibit functional heterogeneity and 2) some DMN subregions respond in a percept-related manner to pain, suggesting closer linkage between the DMN and pain processing than previously thought. Future studies should apply a similar approach using innocuous stimuli of multiple intensities in order to evaluate whether the response profiles reported here can also be generalized to nonpainful somatosensory processing.
\end{abstract}

\footnotetext{
(C) 2012 International Association for the Study of Pain. Published by Elsevier B.V. All rights reserved.

"Correspondence should be addressed to Dr. Marco L. Loggia, Massachusetts General Hospital, Building 120, suite 101E, Charlestown, MA 02129. marco@nmr.mgh.harvard.edu; Phone: +1 617-643-7267; Fax: +1-617-643-7340.

The authors have no conflicts of interest to declare.
}

Publisher's Disclaimer: This is a PDF file of an unedited manuscript that has been accepted for publication. As a service to our customers we are providing this early version of the manuscript. The manuscript will undergo copyediting, typesetting, and review of the resulting proof before it is published in its final citable form. Please note that during the production process errors may be discovered which could affect the content, and all legal disclaimers that apply to the journal pertain. 


\section{Keywords}

cuff pain algometry; psychophysics; neuroimaging; BOLD; default mode network; human

\section{Introduction}

Over the past two decades, neuroimaging studies have identified a widespread network of brain structures activated or deactivated by evoked pain stimuli. Activated regions include primary and secondary somatosensory, anterior cingulate, insular and prefrontal cortices, the thalamus, as well as other regions [1]. Deactivated areas include medial prefrontal cortex, posterior cingulate cortex/retrosplenial cortex, lateral temporal cortex, hippocampal formation and inferior parietal lobule [45], i.e. the 'core' areas of the 'default mode network' (DMN;[11; 49; 66; 69]). However, our understanding of the physiological significance associated with the response within each brain area is still limited. This is particularly true for the pain-related deactivations, which until recently have been relatively neglected [45].

One way to begin disentangling the role of different brain regions in pain processing is to examine their stimulus-response (S-R) function, in the context of stimulations at multiple levels of intensity. This approach is informative as it can potentially distinguish brain regions exhibiting activation/deactivation correlated with perceived pain from those regions in which response magnitude is independent of the perceptual response, and thus less likely to be involved in the encoding of sensory/affective components of pain. Moreover, the shape of the S-R function for brain regions demonstrating pain intensity-dependent activity can provide meaningful information regarding the specific role that each region plays in pain processing.

Several neuroimaging studies have assessed the brain responses to evoked pain stimuli of multiple intensities (e.g., [8; 10; 16; 19; 68; 73]). These studies, however, did not employ more than 3 stimulation levels in the noxious range, thus limiting power for estimating, particularly non-linear, S-R functions. Hence, one of the main aims of our study was to apply statistical methods to effectively tease apart independent linear and nonlinear responses for a larger number (7) of individually calibrated pain levels.

In addition, these previous studies investigated brain responses to cutaneous pain stimuli (e.g. heat, laser, electricity). As most clinical pain originates in deep tissue rather than cutaneous receptors $[12 ; 56]$, the investigation of brain responses to deep tissue pain might prove to be more clinically relevant than brain responses to evoked cutaneous pain. Cuff pressure algometry (CPA) has been successfully adopted as a technique for quantitative sensory testing (e.g., [60-63]). Among the advantages presented by CPA over other more commonly used methods of pain stimulation is that CPA stimuli appear to have a preferential effect on deep tissue nociceptors [62]. However, to our knowledge no functional neuroimaging study has ever evaluated brain responses to CPA.

Thus, the aims of the present studies were twofold: 1) distinguish linear and nonlinear brain responses to evoked pain in both pain-activated and pain-deactivated brain regions, 2) to investigate the brain responses to CPA with functional magnetic resonance imaging (fMRI).

\section{Materials and methods}

\section{Subjects}

Eighteen (18) healthy subjects were recruited to participate in this experiment at the Martinos Center for Biomedical Imaging at Massachusetts General Hospital in Boston, MA, 
USA. Of these subjects, one was excluded at the end of the training session (see below) due to unreliable pain ratings, and one was excluded a posteriori (i.e., upon examination of her fMRI data), due to motion related artifacts. Thus, the data from 16 subjects (11 male, mean age \pm SD: $28.8 \pm 9.7 ; 81.25 \%$ Caucasian, $12.5 \%$ Black/African-American, $6.25 \%$ Asian) were included in all analyses. Exclusion criteria included age below 18 years, left handedness, chronic or acute pain, neurological disorders including peripheral neuropathy, history of significant head injury, serious cardiovascular disease, current use of medications and/or recreational drugs, and contraindications for an MRI study (e.g., presence of metal in the body, pacemakers, neurostimulators, claustrophobia, or pregnancy). All participants in the study provided written informed consent in accordance with the Human Research Committee of the Massachusetts General Hospital. Participants received a total of $\$ 150$ for their participation in both the training and imaging sessions (see below).

\section{Stimulation Procedures}

Subjects participated in two separate sessions, on different days: one training (behavioralonly) session and one imaging session. In both training and imaging sessions, series of $14 \mathrm{~s}$ pressure stimuli (2s ramp up, 10s at target pressure, $2 \mathrm{~s}$ ramp down; Figure 1A) were delivered on the left calf using a $13.5 \mathrm{~cm} * 82.5 \mathrm{~cm}$ velcro-adjusted pressure cuff (SC12D, Hokanson Inc, Bellevue, WA, USA), connected to a rapid cuff inflator (Hokanson E20 AG101, Hokanson Inc, Bellevue, WA, USA). The cuff inflator was adapted to ramp up more gradually to target pressure over $\sim 2$ seconds, to minimize abrupt subject motion. Unlike other methods to elicit deep tissue pain (e.g., intramuscular injections or infusions of hypertonic saline; [12;30-32; 56; 80]), cuff pressure algometry offers more precise control over the onset and offset of pain, and therefore appears better suited for BOLD fMRI studies with block or event-related designs. Pilot, unpublished studies in our lab have in fact shown that these stimuli cause rapid-onset pain responses, which drop back to nil immediately following pressure release. Previous studies have shown that most subjects define cuffinduced pain as deep [60], validating the preferential effect of this type of stimulation on deep tissue nociceptors [62]. However, we cannot definitively exclude the possibility that some cutaneous nociceptors were also affected.

Ten (10) seconds after the end of each stimulus, subjects used a button box to complete two pain rating scales, both on 0-100 numerical scales each displayed for 10 seconds using EPrime software (v. 1.1, Psychology Software Tools, Sharpsburg, PA): pain intensity ( $0=$ 'no pain', $100=$ 'the most intense pain tolerable' $)$ and pain unpleasantness $(0=$ 'neutral', $100=$ 'extremely unpleasant'). Subjects were trained to distinguish intensity and unpleasantness of pain using a brief text similar to that employed by Price and colleagues [65], a method shown to allow dissociation between sensory and affective components of the pain experience [48; 77; 78].

\section{Training session}

The training session was used to familiarize subjects with the stimuli and rating procedures, assess the stability of subjective ratings, and determine appropriate stimulus intensities to be used subsequently in the imaging session (see below).

After providing informed consent, subjects comfortably sat on a chair with the left foot resting on a support at a slightly elevated position (but at a lower level than that of the hips, in order to facilitate blood circulation in the leg). The vascular cuff was then secured around the left calf. The quantitative sensory testing began with an ascending series of stimuli: starting at $60 \mathrm{mmHg}$, a sequence of stimuli with increasing intensity (20 $\mathrm{mmHg}$ increments) was delivered until a pain intensity rating of $\sim 70 / 100$ was first obtained. A descending series was then administered: starting with the last stimulus delivered during the ascending series, 
a sequence of stimuli with decreasing intensity (20mmHg decrements) was delivered until a pain intensity rating of 0 was obtained. For each of the pressures used, the average of the ratings obtained in the ascending and descending series was calculated, and then plotted against the corresponding pressure level to obtain a first 'approximate' S-R curve. From this curve, the pressure values corresponding to pain intensity ratings of 10, 20, 30, 40, 50, 60 or 70/100 (i.e. , 'p10' to 'p70') were obtained by interpolation, using the DPlot Jr software (v. 2.2.7.3, HydeSoft Computing, LLC, Vicksburg, MS). In addition, the highest pressure value which was consistently rated as non-painful (i.e., associated with a pain intensity rating of 0 in both ascending and descending series) was selected as 'p0'. As the awareness that the next stimulus will be higher (or lower) is likely to bias the ratings, a new stimulus-response curve was then calculated based on the ratings recorded during the presentation of the p0p70 stimuli in pseudorandom order. From this new curve, the adjusted p0-p70 stimulus pressures were determined by interpolation.

At the end of this calibration phase, the subjects received each of the p0-p70 stimuli three times, for a total of 24 stimuli. The stimuli were delivered in a pseudorandom order in three separate runs (8 stimuli per run), identical to those of the imaging session (Figure 1A). Based on this testing, subjects were eligible for participation in the imaging session if they were reliably able to perceptually differentiate stimuli of different intensity (i.e., if they reported increasing pain intensity ratings in response to stimuli of increasing intensity). The training session had the effect of rendering the subjects non-naïve to the experimental conditions in the imaging session, an aspect that might be argued to have some impact on the imaging results (particularly with regard to brain activity underlying cognitive and emotional functions). However, this behavioral session allowed several advantages that we believe outweighed these concerns, and were of particular importance for this type of experiment: (1) the identification and exclusion of individuals with unstable ratings, (2) a thorough training in the use of rating scales, and (3) the reduced potential for developing experiment-related anxiety and head motion in the imaging session.

\section{Imaging session}

On the day of the imaging session, the $\mathrm{p} 0-\mathrm{p} 70$ pressures were briefly recalibrated prior to scanning, using procedures similar to those adopted during the training session. The first "approximate" S-R curve, however, was calculated based on the ratings of p0, p10, p40 and p70 from the training session (instead of the full ascending and descending series). The p0p70 stimuli pressures interpolated from this curve were then presented in a pseudorandom order, which allowed the calculation of an adjusted S-R curve. The definitive p0-p70 stimuli pressures to be used during fMRI were determined by interpolation from this latter curve.

During the fMRI scan runs, subjects received each of the p0-p70 stimuli three times, for a total of 24 stimuli. Just as in the training session, during the imaging session the stimuli were delivered in a pseudorandom order in three separate runs (8 stimuli per run). Each stimulus preceded by a $4 \mathrm{~s}$ visual cue (a cross changing color from black to green) which signaled the incoming stimulus to limit stimulus-onset startle reflex. Ten seconds after stimulus offset subjects were presented with the intensity and unpleasantness scales, each for ten seconds (Figure 1A).

\section{Behavioral data analysis}

All the statistical analyses for the behavioral data were performed with Statistica 10.0 (StatSoft Inc., USA), using an alpha level of 0.05. Pain ratings were averaged, for each subject, across the 3 trials for each stimulus pressure, for both pain intensity and unpleasantness separately. In order to determine whether each pressure evoked the target perceptual response, single-sample t-tests were performed to compare the ratings against 
their target value (e.g., 50 for the ratings evoked by p50). The effects of pressure on VAS ratings were then evaluated using a mixed ANOVA, including the factors Stimulus ('p0' to 'p70') and Sex, as within- and between-subject factors, respectively. Post-hoc pairwise comparisons were performed using Tukey's test.

\section{fMRI data acquisition and analysis}

FMRI data were acquired using a 3 T Siemens TIM Trio MRI System (Siemens Medical, Erlangen, Germany) equipped for echo planar imaging with a 32-channel head coil. A whole brain $\mathrm{T} 2 *$-weighted gradient echo BOLD EPI pulse sequence was used $(\mathrm{TR} / \mathrm{TE}=2 \mathrm{sec} / 30 \mathrm{~ms}$, f.a. $=90^{\circ}, 32$ AC-PC aligned axial slices, voxel size $\left.=3.1 \times 3.1 \times 4 \mathrm{~mm}\right)$. Anatomical data were also collected using a multi-echo MPRAGE pulse sequence (TR/TE1/TE2/TE3/ $\mathrm{T} 4=2530 / 1.64 / 3.5 / 5.36 / 7.22 \mathrm{~ms}$, flip angle $=7^{\circ}$, voxel size $=1 \mathrm{~mm}$ isotropic).

FMRI data processing was carried out using FEAT (FMRI Expert Analysis Tool) Version 5.98, part of FSL (FMRIB's Software Library, www.fmrib.ox.ac.uk/fsl). The following preprocessing was applied: motion correction using MCFLIRT [35] fieldmap-based EPI unwarping using PRELUDE and FUGUE [34], non-brain removal using BET [71]; spatial smoothing $(\mathrm{FWHM}=5 \mathrm{~mm})$, grand-mean intensity normalization by a single multiplicative factor, and high-pass temporal filtering (Gaussian-weighted least-squares straight line fitting, with sigma $=29 \mathrm{~s}$ ). Time-series statistical analysis was carried out using FILM with local autocorrelation correction [83]. Cortical surface reconstruction was performed using FreeSurfer (http://surfer.nmr.mgh.harvard.edu/; [18; 25]) for improved structural-functional co-registration and visualization purposes. The transformation matrix for the registration to the high resolution anatomical image was computed using FreeSurfer's bbregister tool, a recent advance that has been shown to improve functional/structural co-registration through an automated algorithm [28]. Computation of the transformation matrix for the registration to the MNI152 standard space, as well as application of both transformation matrices, was carried out using FSL's FLIRT [35; 36].

A first level within-subject general linear model (GLM) analysis was performed by modeling each of the 24 stimuli as independent block regressors, as well as the two $10 \mathrm{~s}$ rating periods (intensity and unpleasantness rating) following each stimulus. A canonical double-gamma hemodynamic response function was adopted. Parameter estimates and relative variances for each stimulus were then passed up to a second level GLM analysis. This second level GLM analysis used several orthogonal regressors corresponding to linear and non-linear transformations of subjects' pain intensity ratings (we did not repeat the analysis with the unpleasantness ratings, given the high correlation with the intensity ratings). In order to identify linear and nonlinear brain responses to pain, the p10-p70 ratings for each subject were first normalized to a range of -1 to +1 . This was achieved by applying the following transformation to each rating: $2 *(x-\min ) /(\max -\min )-1$. Variables min and max were defined from each subject's individual response data. Each normalized rating was then transformed using Legendre polynomials of order $0(y=1), 1(y=x)$ and $2\left(y=1 / 2\left(3 x^{2}-1\right)\right)$, which are known to be statistically independent within the -1 to 1 range (Figure 1B). The Legendre-transformed ratings for polynomials of order 0,1 , and 2 were then entered as separate explanatory variables in the same design matrix. This approach allowed us to construct a GLM where linear and non-linear effects could be tested without any shared variance between the different regressors, thereby enabling an independent test of linear and nonlinear contrasts [24]. Independence of such tests is an important feature for a design matrix, because a high degree of shared variance between the explanatory variables would compromise parameter estimation, as would have been the case had we modeled exponential or logarithmic responses in addition to the linear S-R pattern. The use of orthogonal polynomials such as Legendre polynomials rendered parameter estimates independent from one another. The transformation of the ratings using each of the three polynomial degrees 
allowed the computation of the following contrasts: "Constant" (i.e., with no weighing based on the relative rating, to identify brain areas responding uniformly to the presence of pain, independent of pain intensity), "Linear" (i.e., to identify regions of activity exhibiting a linear relationship with pain ratings) and "Quadratic" (i.e., to identify regions of activity exhibiting a quadratic relationship with pain ratings). Quadratic, U-shaped relationships similar to the one tested here are not unusual in psychophysics and biology. For example, the classical Yerkes-Dodson law describes a U-shaped relationship between arousal levels and performance in a task [86]. Other, more recent examples of U-shaped relationships are found in psychophysical experiments with visual [26; 72], olfactory [17], or tactile stimuli [9]. A few imaging studies employing a combination of innocuous and noxious stimuli have reported U-shaped S-R curves, e.g., in the prefrontal cortex [8; 16]. However, such Ushaped relationships were obtained only when the response to a nonpainful stimulus was included in the curve estimation, and have never been explicitly tested in investigations strictly within the pain continuum. In addition to these Constant, Linear, and Quadratic transformations, a Cubic transformation $\left(\mathrm{y}=1 / 2\left(5 \mathrm{x}^{3}-3 \mathrm{x}\right)\right)$ was also applied for exploratory purposes. However, as this analysis did not yield significant activation/deactivation clusters, it will not be discussed further. We should also note that the exploration of other non-linear $\mathrm{S}-\mathrm{R}$ functions would be interesting as well. For instance, Timmerman and colleagues observed an S-shaped response profile in contralateral S2 [73]. However, there is a high degree of multi-collinearity between these specific non-linear functions and the linear S-R curve, making independent estimation difficult. Finally, as one of the aims of the present work was to identify S-R functions within the noxious continuum, the brain responses to the p0 stimuli were not modeled at this second level stage of the within-subject analysis.

The results of these within-subject analyses were then passed up to group level analyses, performed using FLAME (FMRIB's Local Analysis of Mixed Effects) stage 1 [7; 81; 82]. Group brain maps for constant, linear, and quadratic relationships to increasing pain intensity were threshold using clusters determined by a voxel-wise threshold $(Z>2.3)$ and a (corrected) cluster significance threshold of $\mathrm{P}=0.05$ [84]. In order to minimize the likelihood of false positives, the search volume for all analyses excluded regions corresponding to voxels in the right and left cerebral white matter labels of the Harvard-Oxford Subcortical Structural Atlas (Center for Morphometric Analyses,

http://www.cma.mgh.harvard.edu/fsl_atlas.html) with a value higher than the (arbitrary) threshold of 80. As Sex and the Sex*Stimulus interaction did not have a significant effect on the psychophysical data (see Results below), the factor Sex was not included in the General Lineal Model analyses of the imaging data.

In addition to the whole brain analysis described above, we also performed a region-ofinterest analysis, with a direct search restricted to "pain matrix" regions (i.e., the 5 regions most commonly activated regions in experimental pain studies [1]: primary and secondary somatosensory, insular, anterior and middle cingulate cortices, and the thalamus), as identified with the Harvard-Oxford Atlas. As linearly increasing activation in several of these regions has been reported in previous parametric pain studies (e.g. [2; 3; 8; 16;19;64], we also evaluated the results of our Linear contrast in these regions using an uncorrected threshold of $\mathrm{z}=2.58$, and a minimum cluster size of 5 voxels.

Within each of the statistically significant clusters identified in all contrasts, the $\%$ change in the BOLD signal (\%BOLD) in response to each of the 24 stimuli (including p0, in this case) was extracted from individual peak voxels (i.e., the voxel with the highest $\mathrm{Z}$-value for that specific contrast). Whenever a cluster encompassed two anatomical areas with clearly distinct anatomical-functional properties (e.g., superior and inferior parietal lobule), the search for individual peaks was limited within a mask obtained by raising the threshold of the $\mathrm{Z}$ map until cluster separation was obtained. For subcortical regions (e.g., nucleus 
accumbens, amygdalae, thalami), the search space was delimited by the respective label from the Harvard-Oxford Atlas. Finally, the search space for the anterior and posterior insulae were delimited by manually splitting the insular label from this atlas at the level of the insular central sulcus [53].

For each participant, the \%BOLD extracted from each region, as well as the ratings, were separately averaged across identical pressure levels to increase signal-to-noise ratio in our measurements. For descriptive purposes, the group-averaged \%BOLD for each stimulus level was plotted against the group-averaged ratings to reveal the shape of the stimulus response curve within several regions. Furthermore, the volume-by-volume \%BOLD was plotted against time to create peristimulus plots.

\section{Results}

All subjects tolerated the CPA pain testing, with minimal motion by most subjects. Subjects reported that pain sensation disappeared as soon as cuff pressure was relieved, allowing for repeated testing.

\section{Psychophysical results}

Stimulus pressure had a highly significant linear effect on both ratings of intensity and unpleasantness, F's $(7,98) \geq 81.8$, p's $<0.0001$ (Figure 2), which were statistically correlated ( $r$ 's $\geq 0.65$ ). Neither the intensity ratings nor the unpleasantness ratings were significantly affected by the factor Sex, F's $(1,98) \leq 1.02$, p's $\geq 0.33$, or the Sex*Stimulus interaction, F's $(7,98) \leq 1.1$, p's $\geq 0.36$. Pairwise post-hoc comparisons on the intensity ratings were mostly statistically significant, except that the ratings evoked by $\mathrm{p} 20$ were not statistically different from those evoked by $\mathrm{p} 30(\mathrm{p}=0.30)$ and those evoked by p60 were not statistically different from those of p50 and p70 (p's=0.71 and 0.11 respectively). Similarly, pairwise post-hoc comparisons on the unpleasantness ratings were mostly statistically significant, except that the ratings evoked by $\mathrm{p} 20$ were not statistically different from those evoked by $\mathrm{p} 10$ and $\mathrm{p} 30$ (p's=0.052 and 0.98 ), and those evoked by $\mathrm{p} 60$ were not statistically different from those of p50 and p70 (p's=0.73 and 0.41 respectively).

One-sample t-tests revealed that the p0 to p60 stimuli elicited ratings which were not statistically different from target (p's with Bonferroni correction for multiple comparisons $\left[p_{\text {corr }}\right] \geq 0.05$ ), while $p 70$ produced ratings which were slightly lower than intended (mean=61.6; $\left.\mathrm{p}_{\text {corr }}<0.05\right)$.

The strong cross-correlation between cuff pressure, intensity ratings, and unpleasantness ratings did not allow us to distinguish areas that independently code for these different features. Future studies should attempt to repeat these procedures in conjunction with a cognitive or emotional manipulation aimed at dissociating these components $[48 ; 77 ; 78]$.

\section{Imaging results}

The "Constant" contrast (Figure 3A and Table 1) revealed bilateral activations (i.e., "Constant+") in anterior insula/frontal operculum, medial frontal gyrus (preSMA), and contralateral (right) activations in posterior insula, parietal operculum/S2, dorsolateral prefrontal cortex, lentiform nucleus, inferior and superior parietal lobules.

The same contrast also yielded deactivations (i.e., "Constant-") in a widespread network of structures, including bilaterally over the "core areas" of the default mode network (ventral and dorsal medial prefrontal cortices, posterior cingulate/retrosplenial cortex/precuneus, lateral temporal cortex, hippocampal formation and inferior parietal lobule), as well as amygdalae, thalamus (pulvinar), hypothalamus, pre/postcentral gyri, superior parietal lobule, 
occipital cortex, periaqueductal gray, pons and cerebellum and over ipsilateral (left) paracentral lobule (leg SI/MI), posterior insula, and frontal cortices.

In the whole-brain analysis (Table 1), the "Linear" contrast (Figure 3B and Table 1) revealed contralateral (right) activations (i.e., "Linear+") in the right paracentral lobule, postcentral, precentral and medial frontal (SMA) gyri. Interestingly, the whole-brain Linear contrast analysis also revealed deactivations (i.e., "Linear-") in the right superior and inferior parietal lobules, right lateral temporal cortex, and occipital cortex.

The "Quadratic" contrast (Figure 3C and Table 1) yielded significant bilateral clusters at the level of the dorsal and ventral medial prefrontal cortices, lentiform nucleus, hypothalamus, and substantia nigra, and on the left nucleus accumbens and inferior parietal lobule.

Additionally, our direct search ROI analysis (using commonly activated pain regions from [1]) identified additional regions exhibiting Linear+ responses in portions of the middle/ anterior cingulate and insular cortices (contralateral posterior insula, bilateral anterior insula; Figure 3, gray insert, and Table 2)

We found that several sub-regions within the reported brain areas demonstrated significance for multiple contrasts - i.e. a combination of "Constant" (+ or -) with either "Linear" or "Quadratic" response patterns. For instance portions of R IPL and R LTC showed both the "Constant-" and "Linear-" patterns, portions of MPFC showed both the "Constant-" and "Quadratic" patterns, and portions of insula and MCC showed both "Constant+" and "Linear +". Of note, no region exhibited both a "Linear" and a "Quadratic" component. Multiple response patterns indicate that these regions, while exhibiting a pain intensity-dependent linear activity increase, decrease or $\mathrm{u}$-shaped S-R activity pattern, were overall (i.e., when considering an average of the responses to all pain levels) activated or deactivated during pain.

Figure 4 illustrates the stimulus-response curve and the peristimulus plots (by stimulus intensity) for one representative region from each of the five activity patterns identified by the GLM contrasts (i.e., "Constant+", "Constant-", "Linear+", "Linear-" and "Quadratic"). The examination of the peristimulus plots shows that some regions (e.g., S1/M1 and S2) exhibit activation peaks at both stimulus onset and offset (panels A and C).

Several activity patterns are particularly noteworthy. First, in both posterior insula and paracentral lobule (somatosensory representation of leg) pain-induced activity changes that were of opposite polarity in the two hemispheres: these structures were in fact activated contralaterally, but deactivated ipsilaterally. Additionally, the portions of the SI/MI located outside the paracentral lobule were deactivated bilaterally ("Constant", see Figure 5, green arrows).

Furthermore, exploration of the significant clusters which, among all those identified in the different GLM contrasts, encompassed the core regions of the default mode network [11], reveals that the DMN exhibited 3 distinct region-specific patterns of response to increasingly painful stimuli (Figure 5). Areas such as the posterior cingulate/retrosplenial cortex and hippocampal formation exhibited pain-induced deactivations that appeared to be independent of the perceived pain intensity ("Constant"). In contrast, portions of the right inferior parietal lobule and the right lateral temporal cortex were deactivated in a pain intensity-dependent manner ("Linear"), whereas the activity in regions of the medial prefrontal cortex and the left inferior parietal lobule displayed a quadratic relationship with the perceived pain intensity ("Quadratic"). Interestingly, some areas (e.g., IPL and MPFC) exhibited different response patterns in different subregions. For instance, the MPFC 
displayed a Quadratic response pattern more dorsally, and a Constant- response pattern more ventrally.

\section{Discussion}

Our study demonstrated that brain areas exhibit at least five different pain-related S-R patterns: intensity-independent activation ('Constant+'); intensity-independent deactivation ('Constant-'); linearly increasing ('Linear+'); linearly decreasing ('Linear-'), and 'Quadratic'.

Linearly increasing SI/MI activation replicated other neuroimaging studies (e.g., [16; 19; 64]) and was compatible with electrophysiology studies [14; 41; 42]. A Linear+ profile was also found in the SMA and -in direct searches- in the middle cingulate and insular cortices. Linear response in the insulae was in agreement with previous studies that have described intensity coding of pain in this region $[2 ; 3 ; 8 ; 16]$.

Ultimately, intensity-independent activation in parts of the insula, SII, and other areas may also relate to working memory processes and/or an 'all-or-none' attention/salience response $[20 ; 21 ; 52 ; 58]$, as pain is highly relevant and attracts focused attention at any intensity [23; $68]$.

Interestingly, the paracentral lobule and posterior insula, while activated contralaterally, were also deactivated ipsilaterally. While receiving relatively little attention in pain studies [58], ipsilateral deactivation of SI/MI has been documented during innocuous somatosensory stimulation $[33 ; 39 ; 43 ; 44]$ or during the anticipation of innocuous or noxious stimulation [22]. Previous studies have reported ipsilateral deactivations of the posterior insula during somatosensory stimulation, but only at noxious levels [44]. The functional significance of such deactivations may relate to spatial localization of the stimulus [33], or the suppression of irrelevant sensory information [22; 29; 40; 43; 79]. Similar arguments could apply for the deactivations in SI/MI subregions located outside the leg representation (spatial localization), as well as in the occipital cortex (cross-modal inhibition of visual input).

The 'core regions' of the default mode network exhibited 3 distinct regionally-specific pain response patterns: 'Constant-' (e.g., PCC/Rsp and HF), 'Linear-' (right IPL and LTC) and 'Quadratic' (i.e., e.g., MPFC, left IPL). These observations suggest that DMN subregions, while functionally and anatomically connected and frequently described as co-activated or co-deactivated (e.g. [70]), may in fact exhibit functional heterogeneity. While our formal description of a U-shaped S-R curve in several DMN brain structures (MPFC, left IPL) in relation to pain stimuli was a novel finding, others have reported results that are compatible with our observation. For instance, Derbyshire et al. have observed significant MPFC activity decreases during the application of mild pain stimuli, but not of 'just painful' or moderately painful stimuli [19]. As DMN deactivations linearly increase with increasing attentional demands in multiple tasks [50; 57; 70; 74], this S-R relationship for MPFC may reflect higher cognitive demands associated with the processing pain stimuli in the moderate range, as intermediate pain levels have been found to be more difficult to rate [46]. While we can attempt to speculate on the biological relevance of U-shaped relationships in DMN regions, the existence of this S-R pattern in other brain areas (e.g., the hypothalamus, the substantia nigra and nucleus accumbens) is more difficult to interpret. Future studies should directly explore how these different hypotheses relate to our observation of linear and nonlinear deactivations in response to increasing pain intensity by collecting ancillary data or exploring reaction time metrics in conjunction with pain ratings. 
Several pain-activated regions (i.e., SI/MI and SII) exhibited two activity peaks - at stimulus onset and offset. This phenomenon that has been previously observed in these and other regions in response to noxious [4-6; 13; 43; 59; 76], but also innocuous [43], somatosensory stimulation. While some have claimed that transient responses can be explained in hemodynamic or nonphysiological terms [54; 67], others have proposed a neural origin [27; 75], possibly related to attention/task switching [47]. Therefore, the peaks at onset and offset observed in SI/MI and SII might reflect attentional shifts elicited by changes in the perceptual state.

The observation that the brain exhibits multiple region-specific S-R patterns has several potential implications. For instance, authors have suggested interventions specifically targeting MPFC as a therapeutic strategy to improve cognitive deficits associated with persistent pain [37]. The fact that MPFC displays a quadratic U-shaped S-R pattern supports the use of mid-range stimuli in studies interested in determining an evoked-pain treatment response in this region.

Previous studies have explored different stimulus-response curves in pain processing [8;10; $15 ; 16 ; 55 ; 68]$. Some of the findings in these seminal studies were corroborated by our results, i.e., a stimulus-intensity independent response profile in the posterior parietal and lateral prefrontal cortices and an intensity-encoding profile in portions of the ACC, insula, S1/M1, and ventral SMA. However, notable differences were also observed. For instance, Bornhovd et al. showed that $\mathrm{S} 1$ exhibited an intensity-related profile only at low intensity stimulation, with the response decreasing at the highest pain intensities. Also, this study did not find linearly-dependent deactivations or quadratic responses in the pain continuum. Important methodological differences should be considered when comparing the present study with those previously published. First, in the present study, 7 pain levels were used, versus a maximum of three adopted in previous studies. The use of a larger number of pain levels provided a dense sampling of the S-R curve which, paired with the statistical analyses we adopted, allowed us to more definitively investigate both linear and non-linear S-R patterns. Second, the psychophysical procedures in the present study allowed us to carefully tailor stimulation in order to achieve target perceptual responses, whereas in the studies by Bornhovd et al. fixed stimulus intensities were used. Moreover, while most evoked pain studies use stimuli targeting cutaneous nociceptors (e.g. contact heat or laser), we used cuff pain algometry. Therefore, it is possible that differences in stimulation methodology (e.g., spatiotemporal and qualitative characteristics of the stimuli, differential involvement of large myelinated fibers, etc) might explain some of the differences between this and other studies. For instance, while input from cutaneous receptors is delivered to 'core' neurons of the ventrobasal complex of the thalamus, input from deep tissue receptors is delivered to the "shell" neurons [38]. Since the shell is a very thin structure, it is possible that its activation might be more challenging to image, which might explain why we did not detect any thalamic activations, including in the ventroposterolateral nucleus. Of note, the only painrelated S-R pattern we detected in the thalamus was a 'Constant-' pattern in the pulvinar. As this thalamic nucleus plays an important role in visual and attentional processing [85], deactivation of this structure might reflect attentional switch from the visual cue to the incoming painful stimulus.

Several caveats should be considered when interpreting the results from the present study. First, we employed only one non-painful stimulus level, and therefore could not evaluate whether observed patterns were pain-specific, or also applied to the non-painful somatosensory continuum. As studies have suggested that non nociceptive-specific cognitive processes significantly impact observed fMRI responses to phasic nociceptive stimuli [52], it is possible that at least some of the identified S-R patterns were not painspecific. For instance, the linearly increasing responses in the insula might be due to a 
stimulus intensity estimation independent from pain, as parts of the insula have been recently proposed to serve as a central polymodal magnitude estimation module [3;51]. Future studies will need to apply a similar approach using innocuous stimuli of multiple intensities in order to evaluate whether the response profiles reported here can be generalized to nonpainful somatosensory processing.

Second, it is possible that some brain responses might have been driven by autonomic feedback reflexes induced by cuff vascular constriction, rather than by pain per se. While we observed that $\%$ BOLD signal change was very tightly coupled with perception in several areas (e.g., contralateral S1/M1), which are not strongly linked with autonomic modulation, we cannot exclude that some of the brain responses we observed might have reflected autonomic processing, as some autonomic parameters (e.g. increase in blood pressure) may temporally match the evoked pain profile. Finally, while the S-R curves allow us to speculate on the function of each region highlighted in this study, no psychological measures, other than the psychophysical pain ratings reported here, were collected to corroborate or disprove specific hypotheses.

In conclusion, we present evidence of multiple S-R curve profiles for brain responses to experimental pain, both within areas traditionally associated with pain processing, as well as in the default mode network. Our study provided several important findings including: 1) different DMN subregions, although functionally and anatomically connected and frequently described in the literature as co-activated or co-deactivated, can exhibit functional heterogeneity and 2) some DMN subregions respond in a percept-related manner to pain, suggesting closer linkage between the DMN and pain processing than previously thought. Future experiments will need to test the hypotheses generated based on the observed S-R curves, and also investigate if the S-R curves quantified in the current study in healthy adults are altered in chronic pain patients. Finally, our study investigated, for the first time, brain responses to cuff pressure pain. CPA coupled with fMRI is a promising technique for assessing brain response to evoked pain stimuli, and the preferential effect on deep nociceptors for CPA makes this approach, in theory, more clinically relevant to patients with chronic pain disorders.

\section{Acknowledgments}

We would like to thank NIH for funding support (VN: K01-AT002166, R01-AT004714, P01-AT002048; KP: F05AT003770; AW: 1K23DA020681-01A1), the NCRR (P41RR14075; CRC 1 UL1 RR025758, Harvard Clinical and Translational Science Center). Dr. Park was also supported by the Institute of Information Technology Advancement, Korea IITA-2008-(C1090-0801-0002). Dr. Edwards received support for this study from the American College of Rheumatology and the Arthritis Foundation. The authors would like to thank Drs. Irving Kirsch and Doug Greve for helpful comments on the manuscript. The content is solely the responsibility of the authors and does not necessarily represent the official views of our sponsors.

\section{References}

1. Apkarian AV, Bushnell MC, Treede RD, Zubieta JK. Human brain mechanisms of pain perception and regulation in health and disease. Eur J Pain. 2005; 9(4):463-484. [PubMed: 15979027]

2. Apkarian AV, Hashmi JA, Baliki MN. Pain and the brain: Specificity and plasticity of the brain in clinical chronic pain. Pain. 2010

3. Baliki MN, Geha PY, Apkarian AV. Parsing pain perception between nociceptive representation and magnitude estimation. J Neurophysiol. 2009; 101(2):875-887. [PubMed: 19073802]

4. Becerra L, Breiter HC, Wise R, Gonzalez RG, Borsook D. Reward circuitry activation by noxious thermal stimuli. Neuron. 2001; 32(5):927-946. [PubMed: 11738036]

5. Becerra L, Harris W, Joseph D, Huppert T, Boas DA, Borsook D. Diffuse optical tomography of pain and tactile stimulation: activation in cortical sensory and emotional systems. Neuroimage. 2008; 41(2):252-259. [PubMed: 18394924] 
6. Becerra LR, Breiter HC, Stojanovic M, Fishman S, Edwards A, Comite AR, Gonzalez RG, Borsook D. Human brain activation under controlled thermal stimulation and habituation to noxious heat: an fMRI study. Magn Reson Med. 1999; 41(5):1044-1057. [PubMed: 10332889]

7. Beckmann CF, Jenkinson M, Smith SM. General multilevel linear modeling for group analysis in FMRI. Neuroimage. 2003; 20(2):1052-1063. [PubMed: 14568475]

8. Bornhovd K, Quante M, Glauche V, Bromm B, Weiller C, Buchel C. Painful stimuli evoke different stimulus-response functions in the amygdala, prefrontal, insula and somatosensory cortex: a singletrial fMRI study. Brain. 2002; 125(Pt 6):1326-1336. [PubMed: 12023321]

9. Brisben AJ, Hsiao SS, Johnson KO. Detection of vibration transmitted through an object grasped in the hand. J Neurophysiol. 1999; 81(4):1548-1558. [PubMed: 10200190]

10. Buchel C, Bornhovd K, Quante M, Glauche V, Bromm B, Weiller C. Dissociable neural responses related to pain intensity, stimulus intensity, and stimulus awareness within the anterior cingulate cortex: a parametric single-trial laser functional magnetic resonance imaging study. J Neurosci. 2002; 22(3):970-976. [PubMed: 11826125]

11. Buckner RL, Andrews-Hanna JR, Schacter DL. The brain's default network: anatomy, function, and relevance to disease. Ann N Y Acad Sci. 2008; 1124:1-38. [PubMed: 18400922]

12. Capra NF, Ro JY. Human and animal experimental models of acute and chronic muscle pain: intramuscular algesic injection. Pain. 2004; 110(1-2):3-7. [PubMed: 15275745]

13. Chen JI, Ha B, Bushnell MC, Pike B, Duncan GH. Differentiating noxious- and innocuous-related activation of human somatosensory cortices using temporal analysis of fMRI. J Neurophysiol. 2002; 88(1):464-474. [PubMed: 12091568]

14. Chudler EH, Anton F, Dubner R, Kenshalo DR Jr. Responses of nociceptive SI neurons in monkeys and pain sensation in humans elicited by noxious thermal stimulation: effect of interstimulus interval. J Neurophysiol. 1990; 63(3):559-569. [PubMed: 2329361]

15. Coghill RC, Gilron I, Iadarola MJ. Hemispheric lateralization of somatosensory processing. J Neurophysiol. 2001; 85(6):2602-2612. [PubMed: 11387404]

16. Coghill RC, Sang CN, Maisog JM, Iadarola MJ. Pain intensity processing within the human brain: a bilateral, distributed mechanism. J Neurophysiol. 1999; 82(4):1934-1943. [PubMed: 10515983]

17. Cometto-Muniz JE, Abraham MH. Olfactory detectability of homologous n-alkylbenzenes as reflected by concentration-detection functions in humans. Neuroscience. 2009; 161(1):236-248. [PubMed: 19303922]

18. Dale AM, Fischl B, Sereno MI. Cortical surface-based analysis. I. Segmentation and surface reconstruction. Neuroimage. 1999; 9(2):179-194. [PubMed: 9931268]

19. Derbyshire SW, Jones AK, Gyulai F, Clark S, Townsend D, Firestone LL. Pain processing during three levels of noxious stimulation produces differential patterns of central activity. Pain. 1997; 73(3):431-445. [PubMed: 9469535]

20. Downar J, Crawley AP, Mikulis DJ, Davis KD. A multimodal cortical network for the detection of changes in the sensory environment. Nat Neurosci. 2000; 3(3):277-283. [PubMed: 10700261]

21. Downar J, Mikulis DJ, Davis KD. Neural correlates of the prolonged salience of painful stimulation. Neuroimage. 2003; 20(3):1540-1551. [PubMed: 14642466]

22. Drevets WC, Burton H, Videen TO, Snyder AZ, Simpson JR Jr, Raichle ME. Blood flow changes in human somatosensory cortex during anticipated stimulation. Nature. 1995; 373(6511):249-252. [PubMed: 7816140]

23. Eccleston C, Crombez G. Pain demands attention: a cognitive-affective model of the interruptive function of pain. Psychol Bull. 1999; 125(3):356-366. [PubMed: 10349356]

24. Edwards, AL. Experimental design in psychological research. New York: Holt, Rinehart and Winston; 1968.

25. Fischl B, Sereno MI, Dale AM. Cortical surface-based analysis. II: Inflation, flattening, and a surface-based coordinate system. Neuroimage. 1999; 9(2):195-207. [PubMed: 9931269]

26. Foley JM, Varadharajan S, Koh CC, Farias MC. Detection of Gabor patterns of different sizes, shapes, phases and eccentricities. Vision Res. 2007; 47(1):85-107. [PubMed: 17078992]

27. Gonzalez-Castillo J, Saad ZS, Handwerker DA, Inati SJ, Brenowitz N, Bandettini PA. Wholebrain, time-locked activation with simple tasks revealed using massive averaging and model-free analysis. Proc Natl Acad Sci U S A. 2012; 109(14):5487-5492. [PubMed: 22431587] 
28. Greve DN, Fischl B. Accurate and robust brain image alignment using boundary-based registration. Neuroimage. 2009; 48(1):63-72. [PubMed: 19573611]

29. Haxby JV, Horwitz B, Ungerleider LG, Maisog JM, Pietrini P, Grady CL. The functional organization of human extrastriate cortex: a PET-rCBF study of selective attention to faces and locations. J Neurosci. 1994; 14(11 Pt 1):6336-6353. [PubMed: 7965040]

30. Henderson LA, Bandler R, Gandevia SC, Macefield VG. Distinct forebrain activity patterns during deep versus superficial pain. Pain. 2006; 120(3):286-296. [PubMed: 16427198]

31. Henderson LA, Gandevia SC, Macefield VG. Somatotopic organization of the processing of muscle and cutaneous pain in the left and right insula cortex: a single-trial fMRI study. Pain. 2007; 128(1-2):20-30. [PubMed: 17011704]

32. Henderson LA, Rubin TK, Macefield VG. Within-limb somatotopic representation of acute muscle pain in the human contralateral dorsal posterior insula. Hum Brain Mapp. 2010

33. Hlushchuk Y, Hari R. Transient suppression of ipsilateral primary somatosensory cortex during tactile finger stimulation. J Neurosci. 2006; 26(21):5819-5824. [PubMed: 16723540]

34. Jenkinson M. Fast, automated, N-dimensional phase-unwrapping algorithm. Magn Reson Med. 2003; 49(1):193-197. [PubMed: 12509838]

35. Jenkinson M, Bannister P, Brady M, Smith S. Improved optimization for the robust and accurate linear registration and motion correction of brain images. Neuroimage. 2002; 17(2):825-841. [PubMed: 12377157]

36. Jenkinson M, Smith S. A global optimisation method for robust affine registration of brain images. Med Image Anal. 2001; 5(2):143-156. [PubMed: 11516708]

37. Ji G, Neugebauer V. Pain-related deactivation of medial prefrontal cortical neurons involves mGluR1 and GABA(A) receptors. J Neurophysiol. 2011; 106(5):2642-2652. [PubMed: 21880942]

38. Jones EG, Friedman DP. Projection pattern of functional components of thalamic ventrobasal complex on monkey somatosensory cortex. J Neurophysiol. 1982; 48(2):521-544. [PubMed: 7119861]

39. Kastrup A, Baudewig J, Schnaudigel S, Huonker R, Becker L, Sohns JM, Dechent P, Klingner C, Witte OW. Behavioral correlates of negative BOLD signal changes in the primary somatosensory cortex. Neuroimage. 2008; 41(4):1364-1371. [PubMed: 18495495]

40. Kawashima R, O'Sullivan BT, Roland PE. Positron-emission tomography studies of crossmodality inhibition in selective attentional tasks: closing the "mind's eye". Proc Natl Acad Sci U S A. 1995; 92(13):5969-5972. [PubMed: 7597062]

41. Kenshalo DR Jr, Chudler EH, Anton F, Dubner R. SI nociceptive neurons participate in the encoding process by which monkeys perceive the intensity of noxious thermal stimulation. Brain Res. 1988; 454(1-2):378-382. [PubMed: 3409021]

42. Kenshalo DR Jr, Isensee O. Responses of primate SI cortical neurons to noxious stimuli. J Neurophysiol. 1983; 50(6):1479-1496. [PubMed: 6663338]

43. Klingner CM, Hasler C, Brodoehl S, Witte OW. Dependence of the negative BOLD response on somatosensory stimulus intensity. Neuroimage. 2010; 53(1):189-195. [PubMed: 20538064]

44. Klingner CM, Huonker R, Flemming S, Hasler C, Brodoehl S, Preul C, Burmeister H, Kastrup A, Witte OW. Functional deactivations: multiple ipsilateral brain areas engaged in the processing of somatosensory information. Hum Brain Mapp. 2011; 32(1):127-140. [PubMed: 21157879]

45. Kong J, Loggia ML, Zyloney C, Tu P, Laviolette P, Gollub RL. Exploring the brain in pain: activations, deactivations and their relation. Pain. 2010; 148(2):257-267. [PubMed: 20005043]

46. Kong J, White NS, Kwong KK, Vangel MG, Rosman IS, Gracely RH, Gollub RL. Using fMRI to dissociate sensory encoding from cognitive evaluation of heat pain intensity. Hum Brain Mapp. 2006; 27(9):715-721. [PubMed: 16342273]

47. Konishi S, Donaldson DI, Buckner RL. Transient activation during block transition. Neuroimage. 2001; 13(2):364-374. [PubMed: 11162276]

48. Loggia ML, Mogil JS, Bushnell MC. Experimentally induced mood changes preferentially affect pain unpleasantness. J Pain. 2008; 9(9):784-791. [PubMed: 18538637]

49. Mazoyer B, Zago L, Mellet E, Bricogne S, Etard O, Houde O, Crivello F, Joliot M, Petit L, Tzourio-Mazoyer N. Cortical networks for working memory and executive functions sustain the conscious resting state in man. Brain Res Bull. 2001; 54(3):287-298. [PubMed: 11287133] 
50. McKiernan KA, Kaufman JN, Kucera-Thompson J, Binder JR. A parametric manipulation of factors affecting task-induced deactivation in functional neuroimaging. J Cogn Neurosci. 2003; 15(3):394-408. [PubMed: 12729491]

51. Moayedi M, Weissman-Fogel I. Is the insula the "how much" intensity coder? J Neurophysiol. 2009; 102(3):1345-1347. [PubMed: 19571195]

52. Mouraux A, Diukova A, Lee MC, Wise RG, Iannetti GD. A multisensory investigation of the functional significance of the "pain matrix". Neuroimage. 2011; 54(3):2237-2249. [PubMed: 20932917]

53. Naidich TP, Kang E, Fatterpekar GM, Delman BN, Gultekin SH, Wolfe D, Ortiz O, Yousry I, Weismann M, Yousry TA. The insula: anatomic study and MR imaging display at 1.5 T. AJNR Am J Neuroradiol. 2004; 25(2):222-232. [PubMed: 14970021]

54. Obata T, Liu TT, Miller KL, Luh WM, Wong EC, Frank LR, Buxton RB. Discrepancies between BOLD and flow dynamics in primary and supplementary motor areas: application of the balloon model to the interpretation of BOLD transients. Neuroimage. 2004; 21(1):144-153. [PubMed: 14741651]

55. Oshiro Y, Quevedo AS, McHaffie JG, Kraft RA, Coghill RC. Brain mechanisms supporting spatial discrimination of pain. J Neurosci. 2007; 27(13):3388-3394. [PubMed: 17392455]

56. Owen DG, Clarke CF, Ganapathy S, Prato FS, St Lawrence KS. Using perfusion MRI to measure the dynamic changes in neural activation associated with tonic muscular pain. Pain. 2010; 148(3): 375-386. [PubMed: 19914778]

57. Persson J, Lustig C, Nelson JK, Reuter-Lorenz PA. Age differences in deactivation: a link to cognitive control? J Cogn Neurosci. 2007; 19(6):1021-1032. [PubMed: 17536972]

58. Peyron R, Garcia-Larrea L, Gregoire MC, Costes N, Convers P, Lavenne F, Mauguiere F, Michel $\mathrm{D}$, Laurent B. Haemodynamic brain responses to acute pain in humans: sensory and attentional networks. Brain. 1999; 122 ( Pt 9):1765-1780. [PubMed: 10468515]

59. Ploner M, Gross J, Timmermann L, Schnitzler A. Cortical representation of first and second pain sensation in humans. Proc Natl Acad Sci U S A. 2002; 99(19):12444-12448. [PubMed: 12209003]

60. Polianskis R, Graven-Nielsen T, Arendt-Nielsen L. Computer-controlled pneumatic pressure algometry--a new technique for quantitative sensory testing. Eur J Pain. 2001; 5(3):267-277. [PubMed: 11558982]

61. Polianskis R, Graven-Nielsen T, Arendt-Nielsen L. Modality-specific facilitation and adaptation to painful tonic stimulation in humans. Eur J Pain. 2002; 6(6):475-484. [PubMed: 12413436]

62. Polianskis R, Graven-Nielsen T, Arendt-Nielsen L. Pressure-pain function in desensitized and hypersensitized muscle and skin assessed by cuff algometry. J Pain. 2002; 3(1):28-37. [PubMed: 14622851]

63. Polianskis R, Graven-Nielsen T, Arendt-Nielsen L. Spatial and temporal aspects of deep tissue pain assessed by cuff algometry. Pain. 2002; 100(1-2):19-26. [PubMed: 12435455]

64. Porro CA, Cettolo V, Francescato MP, Baraldi P. Temporal and intensity coding of pain in human cortex. J Neurophysiol. 1998; 80(6):3312-3320. [PubMed: 9862924]

65. Price DD, McGrath PA, Rafii A, Buckingham B. The validation of visual analogue scales as ratio scale measures for chronic and experimental pain. Pain. 1983; 17(1):45-56. [PubMed: 6226917]

66. Raichle ME, MacLeod AM, Snyder AZ, Powers WJ, Gusnard DA, Shulman GL. A default mode of brain function. Proc Natl Acad Sci U S A. 2001; 98(2):676-682. [PubMed: 11209064]

67. Renvall V, Hari R. Transients may occur in functional magnetic resonance imaging without physiological basis. Proc Natl Acad Sci U S A. 2009; 106(48):20510-20514. [PubMed: 19918078]

68. Seminowicz DA, Davis KD. Interactions of pain intensity and cognitive load: the brain stays on task. Cereb Cortex. 2007; 17(6):1412-1422. [PubMed: 16908493]

69. Shulman GL, Fiez JA, Corbetta M, Buckner RL, Miezin FM, Raichle ME, Peterson SE. Common Blood Flow Changes across Visual Tasks: II. Decreases in Cerebral Cortex. J Cogn Neurosci. 1997; 9(5):648-663.

70. Singh KD, Fawcett IP. Transient and linearly graded deactivation of the human default-mode network by a visual detection task. Neuroimage. 2008; 41(1):100-112. [PubMed: 18375149]

71. Smith SM. Fast robust automated brain extraction. Hum Brain Mapp. 2002; 17(3):143-155. [PubMed: 12391568] 
72. Tapia E, Breitmeyer BG, Jacob J. Metacontrast masking with texture-defined second-order stimuli. Vision Res. 2011; 51(23-24):2453-2461. [PubMed: 22037303]

73. Timmermann L, Ploner M, Haucke K, Schmitz F, Baltissen R, Schnitzler A. Differential coding of pain intensity in the human primary and secondary somatosensory cortex. J Neurophysiol. 2001; 86(3):1499-1503. [PubMed: 11535693]

74. Tomasi D, Ernst T, Caparelli EC, Chang L. Common deactivation patterns during working memory and visual attention tasks: an intra-subject fMRI study at 4 Tesla. Hum Brain Mapp. 2006; 27(8):694-705. [PubMed: 16404736]

75. Tyler CW, Kontsevich LL, Ferree TC. Independent components in stimulus-related BOLD signals and estimation of the underlying neural responses. Brain Res. 2008; 1229:72-89. [PubMed: 18625206]

76. Upadhyay J, Pendse G, Anderson J, Schwarz AJ, Baumgartner R, Coimbra A, Bishop J, Knudsen J, George E, Grachev I, Iyengar S, Bleakman D, Hargreaves R, Borsook D, Becerra L. Improved characterization of BOLD responses for evoked sensory stimuli. Neuroimage. 2010; 49(3):22752286. [PubMed: 19854280]

77. Villemure C, Bushnell MC. Mood influences supraspinal pain processing separately from attention. J Neurosci. 2009; 29(3):705-715. [PubMed: 19158297]

78. Villemure C, Slotnick BM, Bushnell MC. Effects of odors on pain perception: deciphering the roles of emotion and attention. Pain. 2003; 106(1-2):101-108. [PubMed: 14581116]

79. Whang KC, Burton H, Shulman GL. Selective attention in vibrotactile tasks: detecting the presence and absence of amplitude change. Percept Psychophys. 1991; 50(2):157-165. [PubMed: 1945737]

80. Wood PB, Schweinhardt P, Jaeger E, Dagher A, Hakyemez H, Rabiner EA, Bushnell MC, Chizh BA. Fibromyalgia patients show an abnormal dopamine response to pain. Eur J Neurosci. 2007; 25(12):3576-3582. [PubMed: 17610577]

81. Woolrich M. Robust group analysis using outlier inference. Neuroimage. 2008; 41(2):286-301. [PubMed: 18407525]

82. Woolrich MW, Behrens TE, Beckmann CF, Jenkinson M, Smith SM. Multilevel linear modelling for FMRI group analysis using Bayesian inference. Neuroimage. 2004; 21(4):1732-1747. [PubMed: 15050594]

83. Woolrich MW, Ripley BD, Brady M, Smith SM. Temporal autocorrelation in univariate linear modeling of FMRI data. Neuroimage. 2001; 14(6):1370-1386. [PubMed: 11707093]

84. Worsley, KJ. Statistical analysis of activation images. In: Jezzard, P.; Matthews, PM.; Smith, SM., editors. Functional MRI: An Introduction to Methods. New York, NY: Oxford University Press; 2001.

85. Wurtz RH, Joiner WM, Berman RA. Neuronal mechanisms for visual stability: progress and problems. Phil Trans R Soc Lon. 2011; 366(1564):492-503.

86. Yerkes RM, Dodson JD. The relation of strength of stimulus to rapidity of habit-formation. J Comp Neurol Psychol. 1908; 18:459-482. 
METHODS

\section{A. EXPERIMENTAL DESIGN}

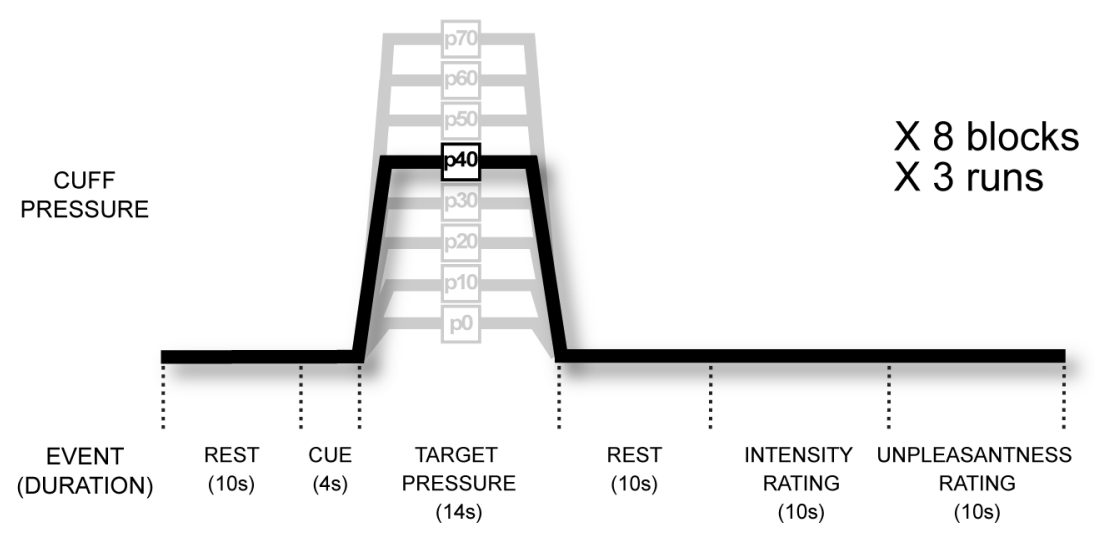

\section{B. LEGENDRE POLYNOMIAL RATINGS TRANSFORMATION (example subject)}

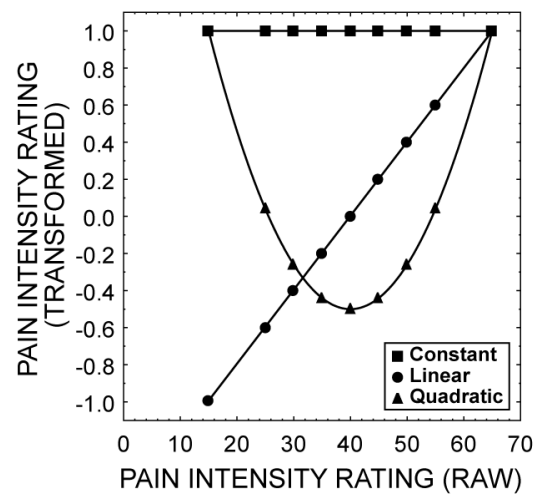

Figure 1. (A) Experiment trial design. (B) Legendre polynomial transformations These transformations were applied to pain ratings in order to produce independent regressors for the fMRI general linear model. 


\section{PSYCHOPHYSICAL RESULTS}
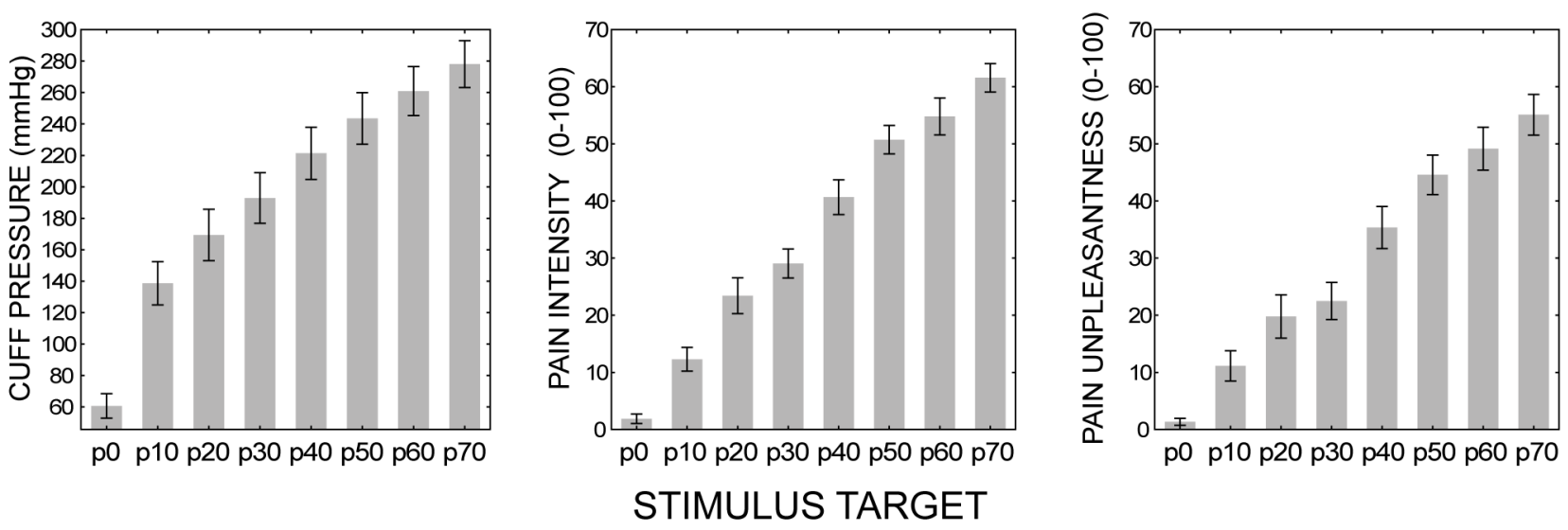

Figure 2. Psychophysical results

Bars represent mean \pm SD. 


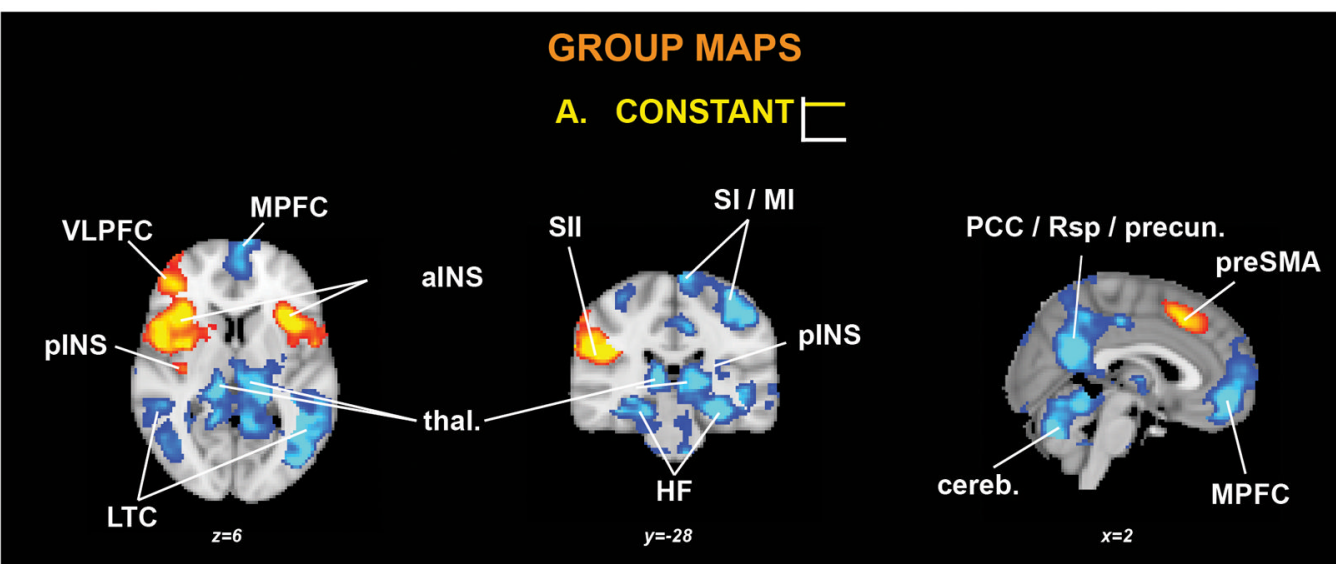

B. LINEAR $\measuredangle$
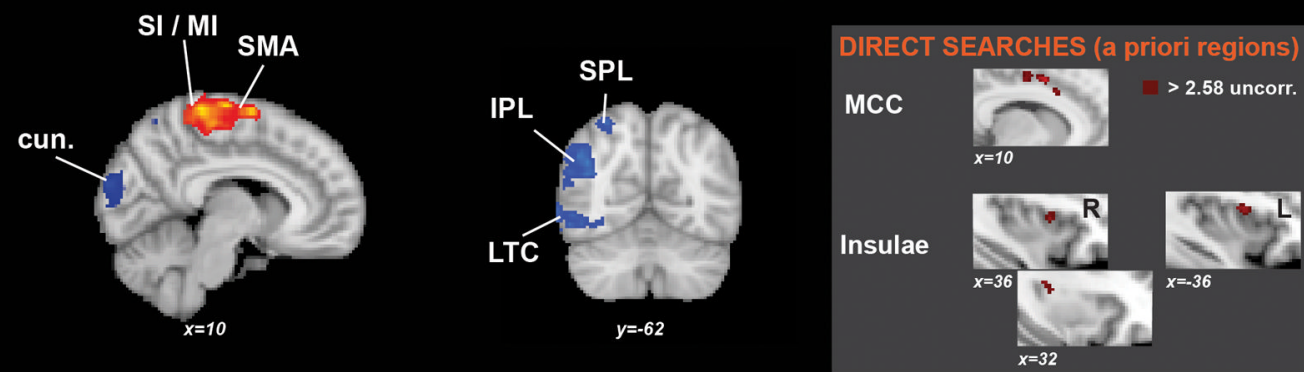

C. QUADRATIC U

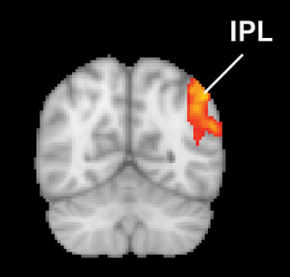

$\mathbf{R}$

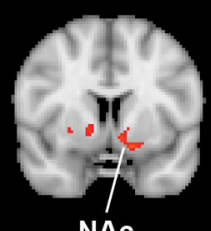

NAc

$y=6$

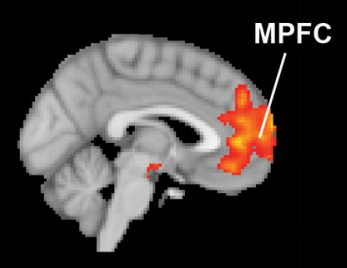

$x=-2$

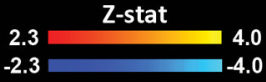

Figure 3. Group statistical maps for the (A) Constant, (B) Linear and (C) Quadratic stimulusresponse curves

The gray insert displays the results of the direct searches in a priori regions (see Methods). $\mathrm{SI} / \mathrm{MI}=$ primary somatosensory/motor cortex, $\mathrm{SII}=$ Secondary somatosensory cortex, $\mathrm{pINS}$ $=$ posterior insula, aINS $=$ anterior insula, $\mathrm{MCC}=$ middle cingulate cortex, $\mathrm{HF}=$ Hippocampal formation, thal. $=$ thalamus, $\mathrm{MPFC}=$ medial prefrontal cortex, VLPFC $=$ ventrolateral prefrontal cortex, $\mathrm{LTC}=$ lateral temporal cortex, cereb. $=$ cerebellum, $\mathrm{PCC}=$ posterior cingulate cortex, Rsp = retrosplenial cortex, precun. $=$ precuneus, IPL = inferior parietal lobule, $\mathrm{SPL}=$ superior parietal lobule, $\mathrm{SMA}=$ supplementary motor area, preSMA $=$ pre-supplementary motor area, cun. = cuneus, NAc $=$ nucleus accumbens. 
REGION

A. R S2 (Constant+)

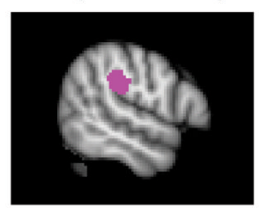

B. PCC / Rsp (Constant-)

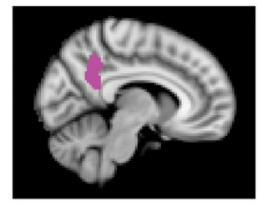

C. R SI / MI (Linear+)

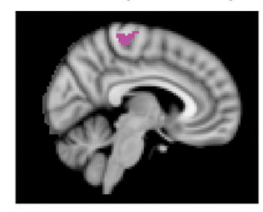

D. R IPL (Linear-)

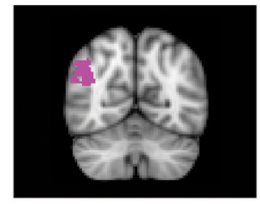

E. MPFC (Quadratic)

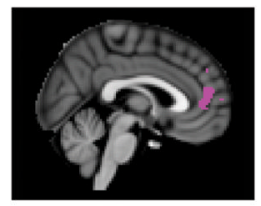

\section{REPRESENTATIVE REGIONS}

S-R CURVE
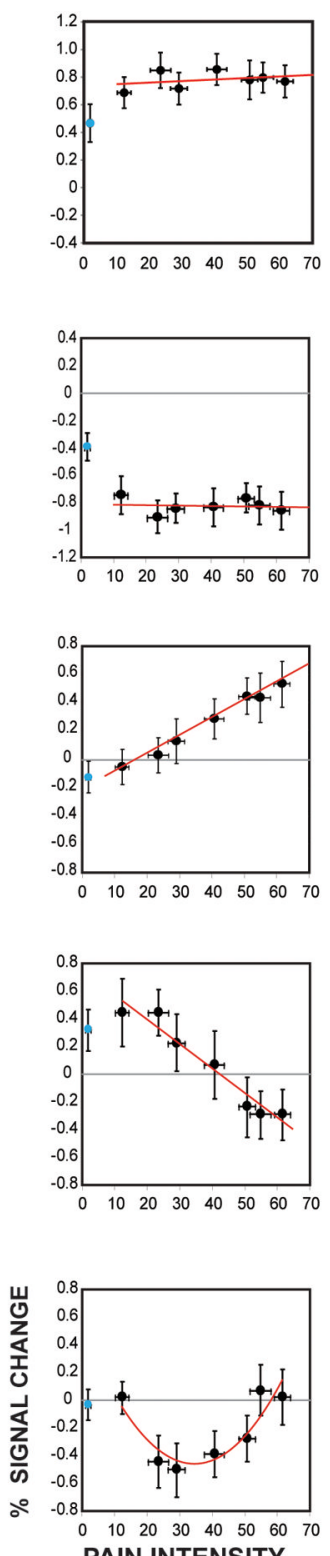

PERISTIMULUS PLOTS
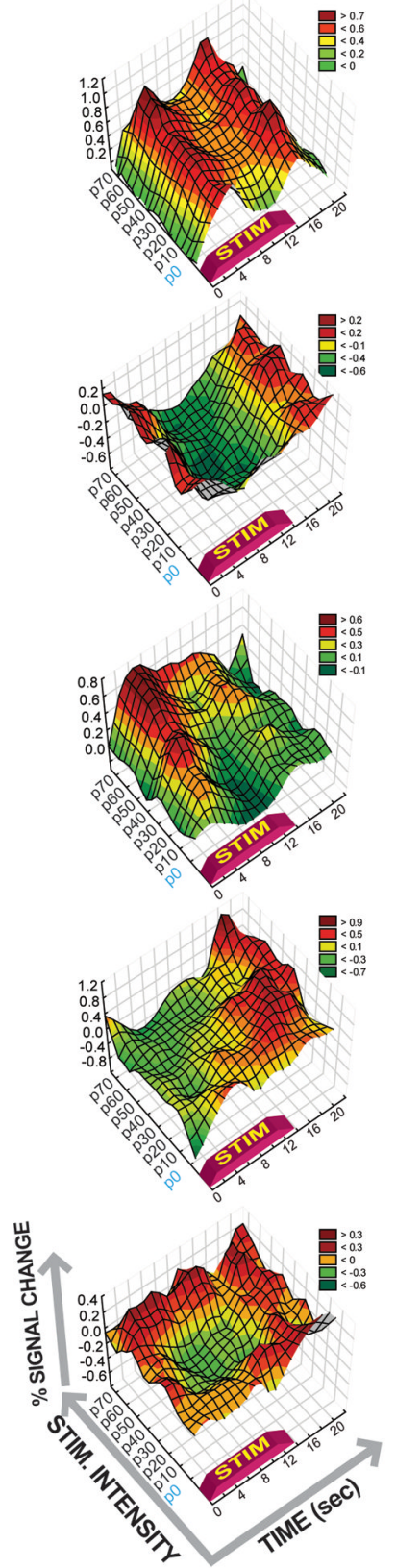

Figure 4. Representative regions for each of the five activity patterns identified (A) S2, (B) PCC/Rsp, (C) right SI/MI, (D) right IPL and (E) MPFC were selected as representative regions for the Constant+, Constant-, Linear+, Linear- and Quadratic contrasts, respectively. The left, middle and right panels show the masks used to extract the $\%$ signal change, the S-R curves, and the averaged peristimulus plots, respectively. In the scatterplots, brain response to innocuous stimuli ('p0', not modeled in the GLM) is represented by cyan circles. Error bars represent SEM. For acronyms and abbreviations, see Figure 3 caption. 


\section{HETEROGENEITY IN PARAMETRIC PAIN RESPONSE AMONG DMN SUBREGIONS}

Constant -

Linear -

Quadratic

L IPL

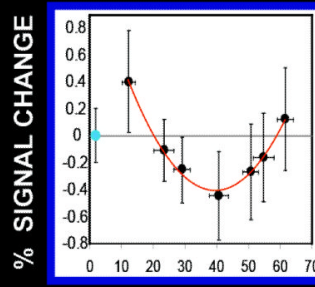

PAIN INTENSITY
R IPL

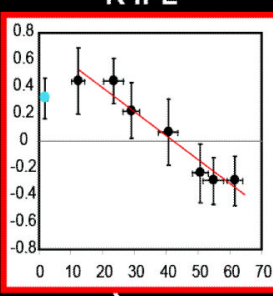

R LTC

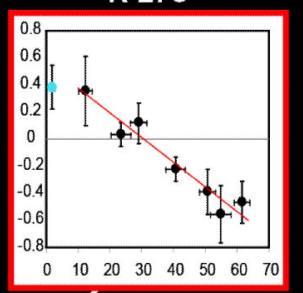

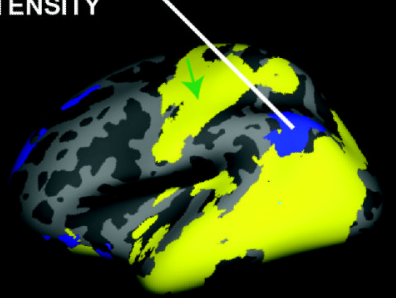
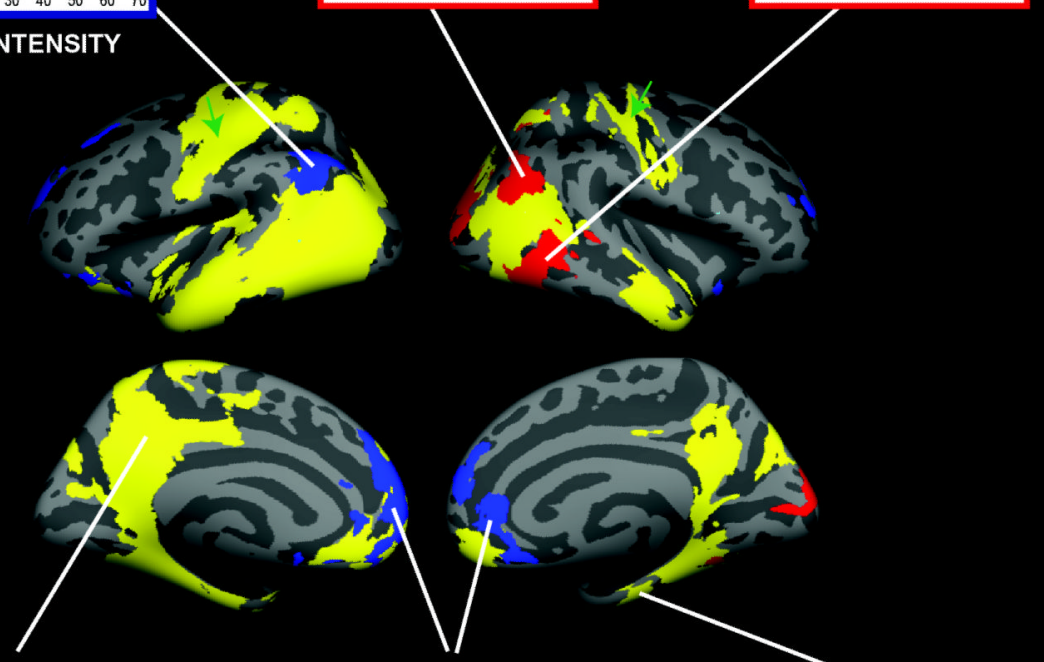

PCC/Rsp

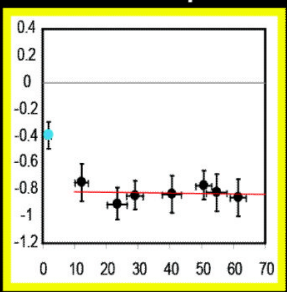

MPFC

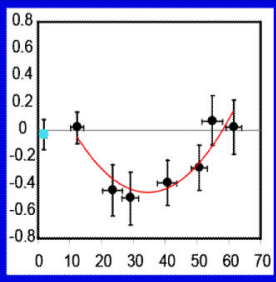

R HF

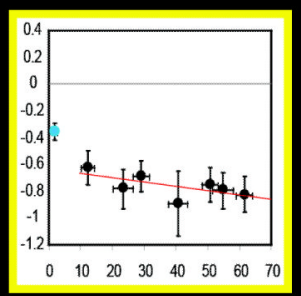

Figure 5. Multifaceted DMN response to pain

Surface representation data demonstrate pain intensity independent deactivation (Constant-) in regions described as DMN 'core' areas, as well as bilateral perirolandic cortices (green arrows). In the scatterplots, the activity changes evoked by innocuous stimuli ('p0', not modeled in the GLM) are represented by cyan circles. $\mathrm{X}$ axes = pain intensity ratings, Y axes $=\%$ BOLD signal change. Error bars represent SEM. For acronyms and abbreviations, see Figure 3 caption. Using functional magnetic resonance imaging, this study identifies five different, regionally-specific activity profiles in the brain in response to seven levels of pain stimulation. 


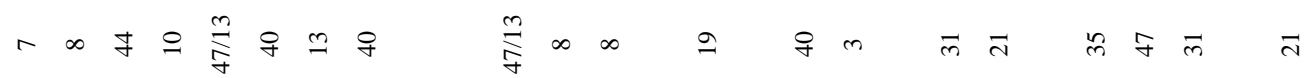




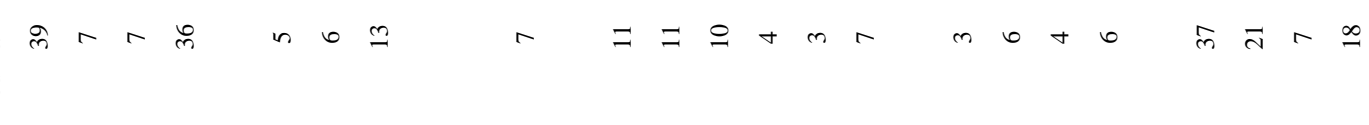

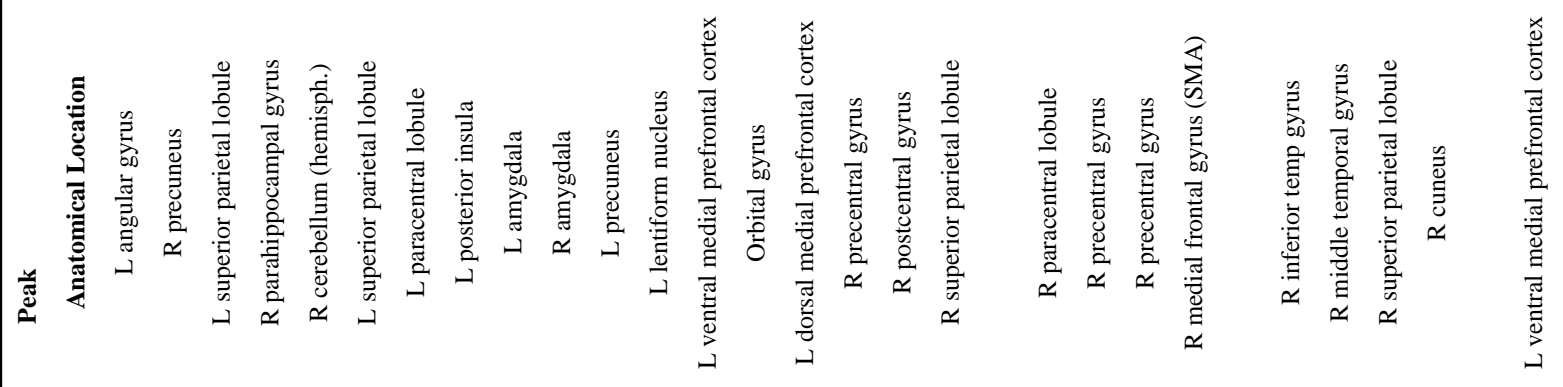

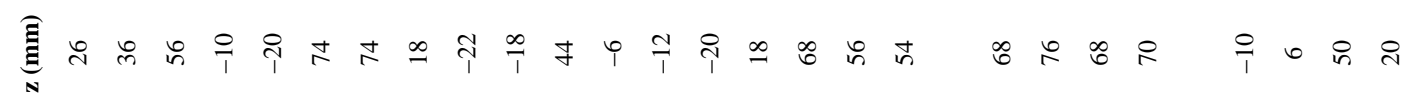

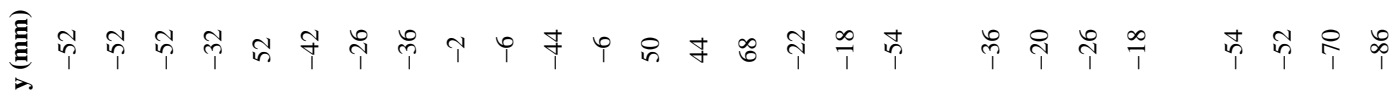

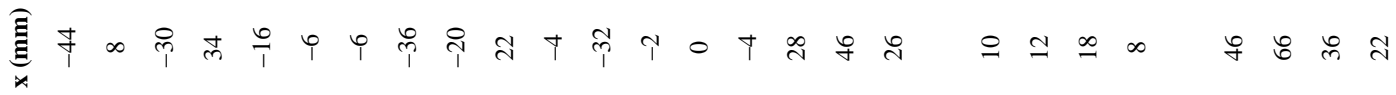

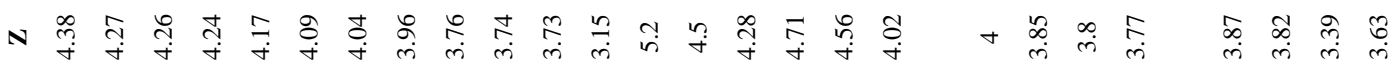




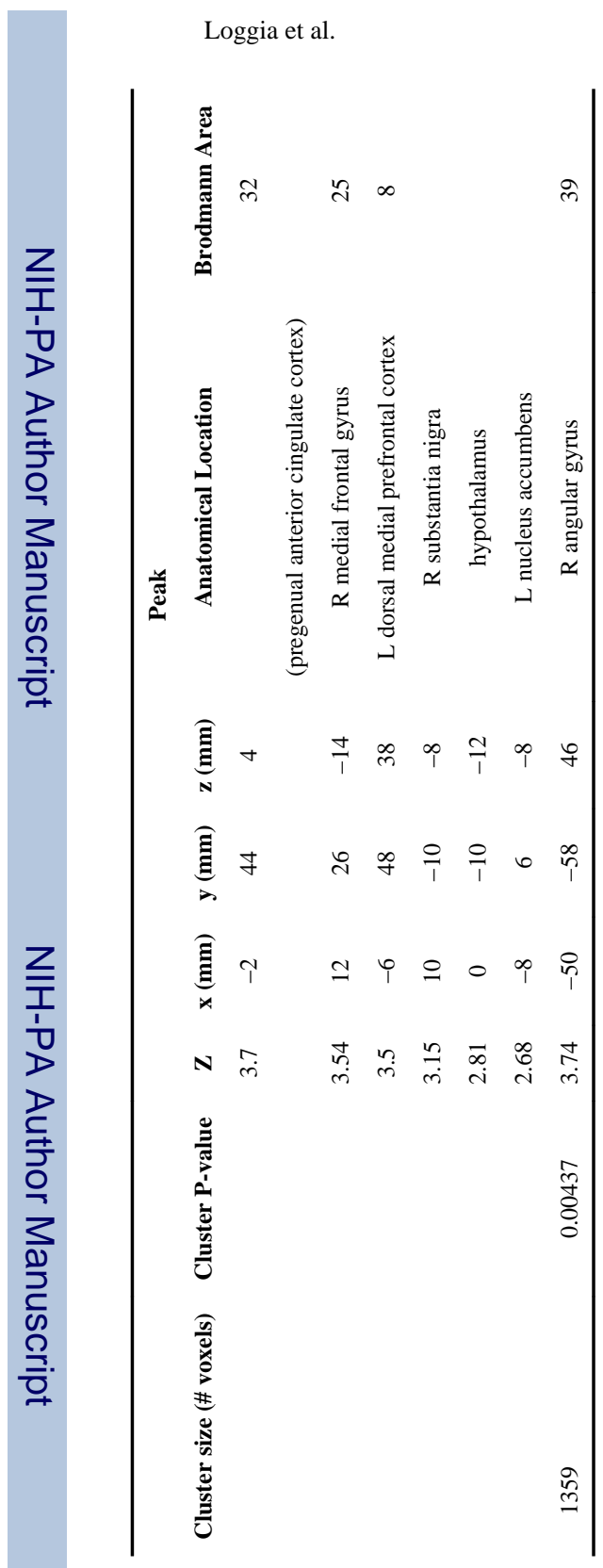

Page 23

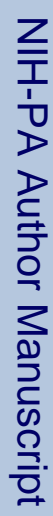

Pain. Author manuscript; available in PMC 2013 October 01. 
